\title{
THE STEREOSPECIFICITY OF THE INOSITOL RECEPTOR OF THE SILKWORM BOMBYX MORI
}

\author{
WILLIAM JAKINOVICH, JR. AND BERNARD W. AGRANOFF \\ Mental Health Research Institute, University of Michigan, Ann Arbor, Mich. 48104 (U.S.A.)
}

(Accepted April 15th, 1971)

\section{INTRODUCTION}

The larva of the silkworm, Bombyx mori, is known to possess a 'sugar-sensitive' hair (Ss-I) together with two other sensilla styloconica on the maxillary lobe. By means of electrophysiological responses, 4 chemosensory neurons have been identified in the Ss-I hair. One, designated $\mathrm{L}_{\mathrm{s}}$, is highly sensitive to sucrose and related sugars, a second $(\mathrm{G})$ responds to D-glucose and related sugars, a third $\left(\mathrm{N}_{1}\right)$ discharges in the presence of various salts, while the fourth $\left(\mathrm{L}_{\mathrm{I}}\right)$ is reported to respond to myo-inositol but not to a variety of other carbohydrates ${ }^{11-13}$. The suitability of cyclitols as model compounds for studying a taste receptor and a general interest in the molecular basis of the vitamin function of myo-inositol throughout the animal kingdom prompted the present study on the $\mathrm{L}_{\mathrm{I}}$ receptor.

\section{MATERIALS AND METHODS}

Cyclitols* were the generous gifts of Dr. S. J. Angyal, University of New South Wales, Australia and Dr. L. Anderson, University of Wisconsin, U.S.A. For evaluation of purity, $20 \mu \mathrm{l}$ of stock cyclitol solution $(0.1 \mathrm{M}$ in $0.02 \mathrm{M} \mathrm{NaCl})$ was dried, then dissolved in $5 \mu$ l of dimethylformamide which had been dried over calcium hydride, and Regisil-TMCS (15 $\mu$ l) (Regis Chemical Co., Chicago, Ill.) was added. The mixture was shaken for $2 \mathrm{~h}$ in tightly closed Microflex vials (Kontes Glass Co., Vineland, N.J.). A volume of $1 \mu \mathrm{l}$ or less was then injected into a gas chromatograph equipped with a hydrogen flame detector and an Apiezon column, heated to $200^{\circ} \mathrm{C}$. Retention times for trimethylsilyl ethers of the cyclitols ranged from 3.4 to $10 \mathrm{~min}$. The samples used had less than $1 \%$ detectable contamination.

Silkworm eggs were purchased from Turtox (Chicago, Ill.) and were raised in spring and summer on fresh mulberry leaves obtained locally. In a winter experiment,

* IUPAC-IUB tentative cyclitol nomenclature rules were used where applicable, Biochem. J., 112 (1969) 17-28. 
5th instar larvae were obtained through the generous cooperation of Dr. J. McBain Cameron of Sault Ste. Marie, Canada. Freshly moulted, unfed, 5th instar larvae of the silkworm were used throughout these experiments. Afferent impulses associated with the chemoreceptor neurons were recorded by techniques developed for use with the fly ${ }^{10}$ that had been adapted for use with the silkworm ${ }^{11}$. The severed head of a larva was mounted upon a platinum pin which acted as the indifferent electrode. The recording electrode, a similar piece of $1.7-\mathrm{mm}$ diameter platinum wire, was inserted into a piece of glass capillary tubing forming electrical contact with a $0.02 \mathrm{M} \mathrm{NaCl}$ solution. This solution, which contained the compound being tested, was transferred from a storage vial to the capillary tubing by means of a micropipet a few seconds before the test. The platinum wire was connected to a high-input impedance cathodefollower preamplifier followed by an AC amplifier. Action potentials were displayed on an oscilloscope from which they were photographed for later analysis. Hairs were first tested to see if they responded to the saline solution and then to $0.01 \mathrm{M} \mathrm{myo-}$ inositol in $0.02 \mathrm{M} \mathrm{NaCl}$. Any animal that responded to the $\mathrm{NaCl}$ or showed erratic discharge with myo-inositol was rejected. Test solutions were always presented in order of increasing concentration. Each hair was tested with $0.01 \mathrm{M} \mathrm{myo-inositol} \mathrm{at}$ intervals to determine if it was still responding optimally. At least $5 \mathrm{~min}$ between tests was allowed for disadaptation. All experiments were performed at $22 \pm 2^{\circ} \mathrm{C}$.
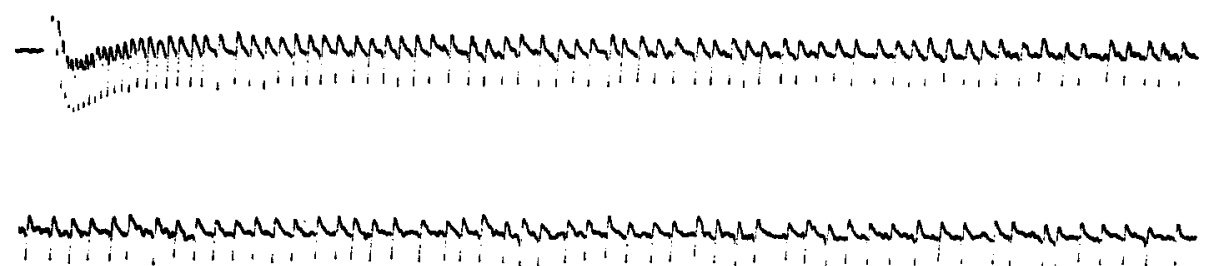

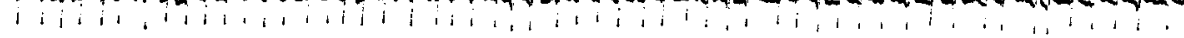
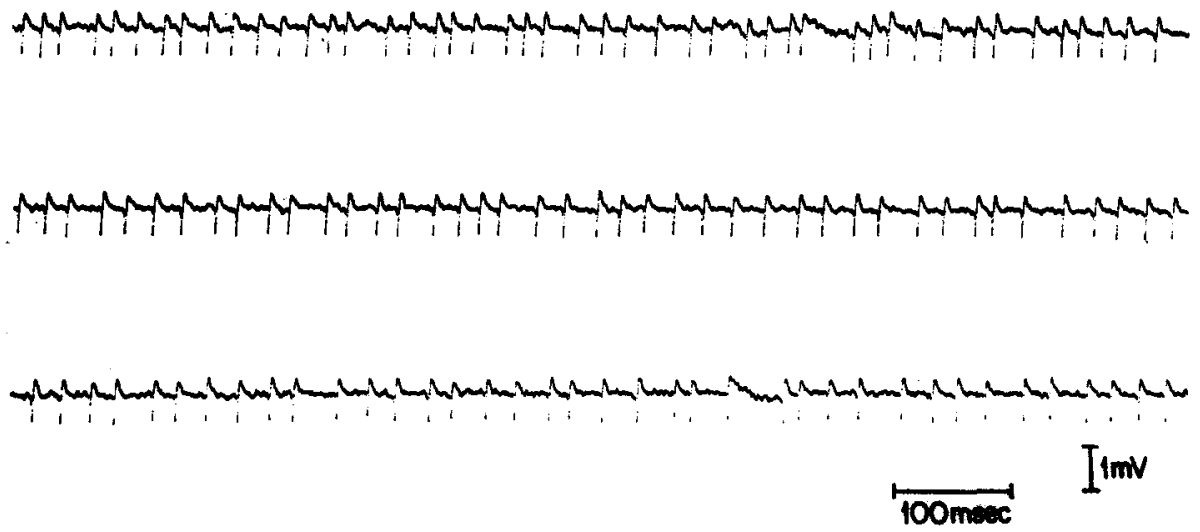

Fig. 1. Response of the $\mathrm{L}_{\mathrm{I}}$ receptor neuron to $0.01 M$ myo-inositol. Positive polarity at the recording electrode is represented by a downward deflection. Application of stimulus is indicated by artifact at the beginning of record. 


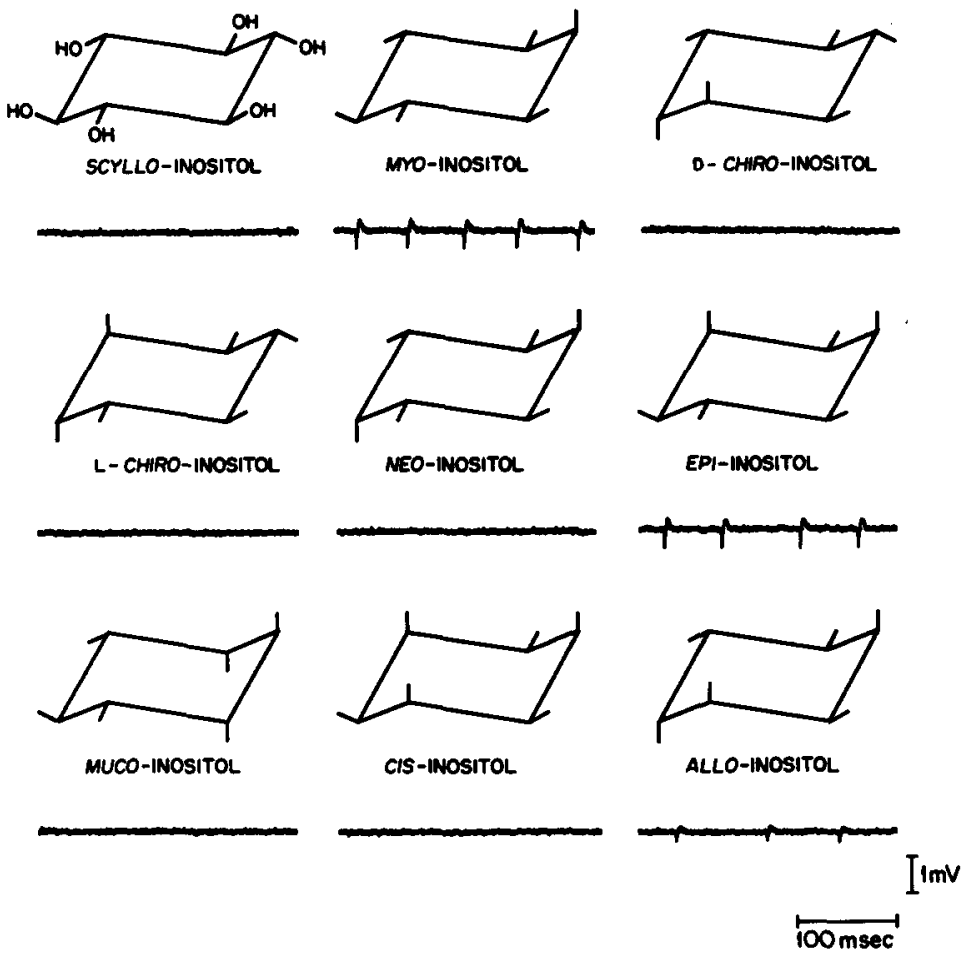

Fig. 2. Response of the receptor neurons in the Ss-I hair to the 9 different cyclitols at $0.01 M$. Records with no activity indicate the failure of any receptor neuron contained within the Ss-I hair to respond to the applied stimulus.

\section{RESULTS}

The typical response of an $\mathrm{L}_{\mathrm{I}}$ neuron to $0.01 M$ myo-inositol was characterized by a high initial burst that declined to a steady lower rate over the course of a few seconds (Fig. 1). This steady level was on occasion maintained for over $15 \mathrm{~min}$ before gradually adapting. Of the 9 cyclitols only myo-, epi-and allo-inositol elicited receptor activity (Fig. 2). In order to verify which receptor each cyclitol was stimulating, various mixtures of the 3 active cyclitols and sucrose were applied to the sensory hair. The mixed solutions were allowed to reach the steady level, at which time recognition of different spike heights characterizing their sensory neurons was greatly facilitated (Fig. 3). In the chemosensory hair, the spike height of the $\mathrm{L}_{\mathrm{I}}, \mathrm{L}_{\mathrm{B}}$, and other receptor neurons differs sufficiently to allow identification of a given spike with its receptor. The records indicated clearly that the $\mathrm{L}_{I}$ spike is larger than the $\mathrm{L}_{\mathrm{g}}$ spike. The $\mathrm{L}_{\mathrm{I}}$ neuron responded only to myo- and epi-inositol. Allo-inositol stimulated a different neuron whose spike height appeared to be smaller than the $L_{\mathbb{B}}$ neuron, possibly the $G$ neuron ${ }^{11}$. Recordings showed occasional similar spikes when sucrose or myo-inositol was being tested.

Response was determined as the average frequency during a $3 \mathrm{sec}$ interval of stimulation after the receptor had reached a nearly steady level. Analysis of results 
A

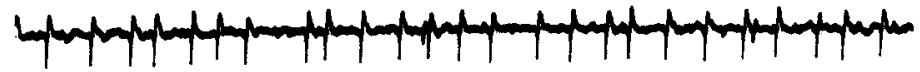

B

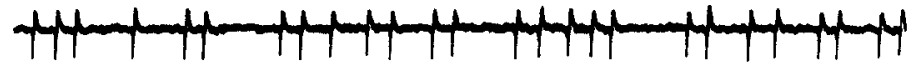

C

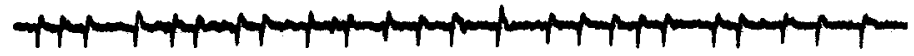

D

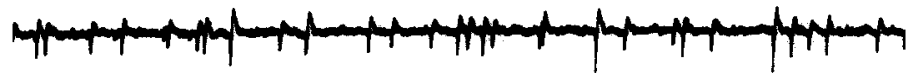

E

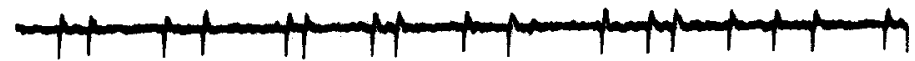

\section{$F$}

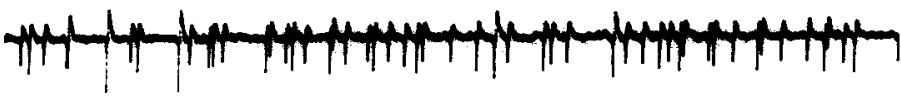

$\stackrel{100 \text { maec }}{1 \mathrm{fmV}}$

Fig. 3. $\mathrm{L}_{\mathrm{I}}$ and $\mathrm{L}_{\mathrm{s}}$ receptor activity evoked by cyclitols and sugar mixtures. A, myo-inositol; B, epiinositol; C, sucrose; D, sucrose + myo-inositol; E, epi-inositol + myo-inositol; F, epi-inositol +sucrose. Large spikes are electrical summation of the $L_{I}$ and $L_{s}$ spike. The final concentration of each substance was $0.1 \mathrm{M}$.

from mixtures of myo- and epi-inositol showed that their effects were completely additive, consistent with the interpretation that both molecules are acting at a common site. Threshold and magnitude of response of the $L_{I}$ receptor were very nearly the same for both cyclitols in the same animal (Fig. 4). A plot of concentration per response versus concentration ${ }^{2}$ showed identical slopes and intercepts for myo- and epi-inositol (Fig. 4, inset).

\section{DISCUSSION}

In adult flies, both behavioral ${ }^{5,6}$ and electrophysiological ${ }^{9,15}$ studies have indicated the presence of a labellar chemoreceptor neuron that is highly specific for glucopyranosides. Previous studies ${ }^{15}$ suggested to us that the cyclitol, myo-inositol, as well as its isomers, might be particularly suitable model compounds for the study of the stereospecificity of sugar receptors in the fly because of the relatively simple chemistry of the cyclitols compared to the sugars.

The cyclitols comprise the 9 possible configurational isomers of hexahydroxycyclohexane and are believed to exist in the chair form in which the maximal possible number of hydroxyls are equatorial. Allo-inositol may form two equally probable 


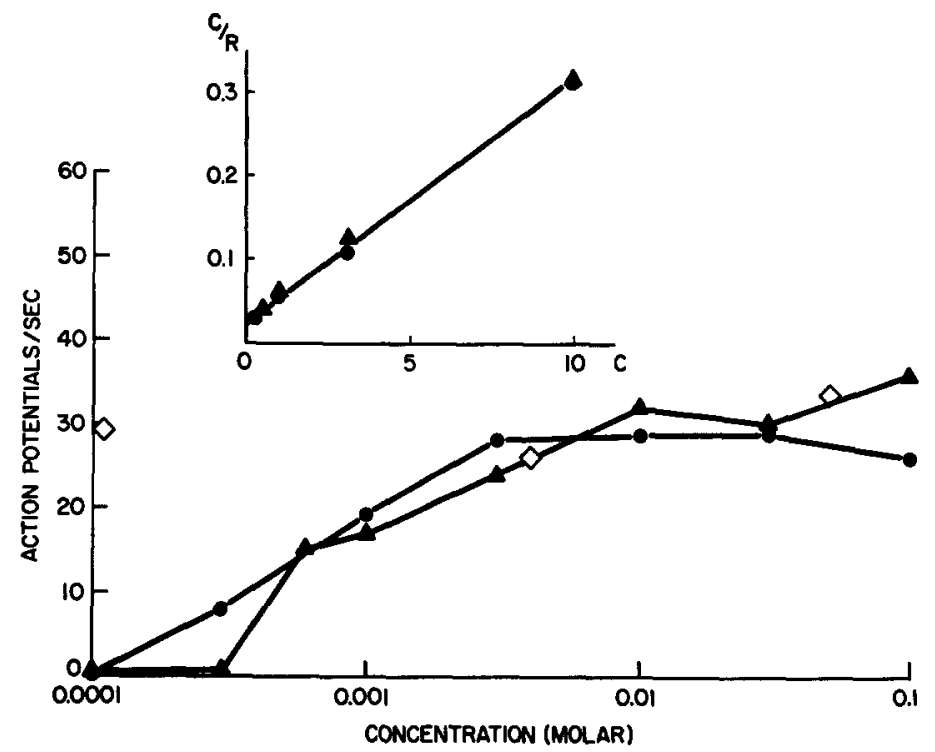

Fig. 4. Comparison of response-concentration relation in stimulation by myo-inositol (O) and epiinositol $(\Lambda)$. The receptor was stimulated with $0.01 M$ myo-inositol $(\diamond)$ periodically as shown to check the reproducibility of the magnitude of the full response. Inset is a plot of these data according to Beidler ${ }^{2} \mathrm{C}=$ molar concentration $\times 10^{-3} ; \mathrm{R}=$ response in action potentials per sec; slope is $1 / R_{m}$, $R_{m}$ being maximal response and $\left(1 / R_{m}\right) \times(1 / K)$ is the y intercept, where $\mathrm{K}$ is the equilibrium constant. The ordinate $C / R$ is $\times 10^{-3}$.

enantiomorphic chairs and is therefore a racemic mixture, considered here as one of the 9 isomers. Unlike the sugars, the cyclitols do not present the problems of open chain, furanoside and pyranoside interconversion, or are there anomeric positions. They therefore make up a highly suitable series for comparison of biological activity.

It is well established that only the myo-isomer fulfills a vitamin function in a wide variety of systems ${ }^{18}$ although the molecular basis for this specificity is not known. One major role appears to be the synthesis of the structural phospholipid, phosphatidyl inositol via reaction of the free cyclitol with cytidine diphosphate diglyceride ${ }^{1,17}$. In guinea pig brain, only myo-inositol reacts with the enzyme, cytidine diphosphate diglyceride: inositol transferase ${ }^{3}$. Of interest, the locust contains considerable quantities of scyllo-inositol, but the phosphatidyl inositol in its membranes contains only the myo-isomer ${ }^{4}$.

From the present results, we can infer the steric requirements of the silkworm cyclitol receptor. Myo-inositol has a single axial hydroxyl at C2. Since scyllo-inositol (all hydroxyls equatorial) does not stimulate the receptor, a requirement for the axial hydroxyl (or equatorial hydrogen) at C2 is established. Since neither D- nor L-chiroinositol are effective, requirements for equatorial hydroxyls at positions 1 and 3 are indicated. The failure of muco-inositol, which has axial hydroxyls at both $\mathrm{C} 1$ and $\mathrm{C} 3$, to stimulate the receptor further supports this notion. In the experiment with neoinositol, the results indicate that C5 must also have an hydroxyl in the equatorial position to be effective, while the results with cis-inositol show that when both $\mathrm{C} 4$ and C6 have axial hydroxyls, the cyclitol is not stimulatory. Since epi-inositol is fully active, 
it would seem that if $\mathrm{C} 4$ or $\mathrm{C} 6$ (but not both) has one axial hydroxyl while the other hydroxyl is equatorial, there is full activity. The minimal configurational requirement for a stimulatory cyclitol appears then at present to include one axial hydroxyl at $\mathrm{C} 2$ and equatorial hydroxyls at C1, C3, C5 and either C4 or C6. Further elucidation of the specificity could be derived from studies with deoxycyclitols to establish whether there is a requirement for an axial hydroxyl at $\mathrm{C} 2$ or whether the equatorial hydroxyl is blocking. In the fly, methyl $a$-D-glucopyranoside stimulates the sweet receptor. Like inositol, it has one axial substituent. Methyl $\beta$-D-glucopyranoside, which by analogy resembles scyllo-inositol, is much less effective. Significantly, 1-deoxy-D-glucopyranoside (1,5-anhydro-D-glucitol) is also stimulatory in the fly ${ }^{6,15}$. It may ultimately mean that the Bombyx cyclitol receptor is relatively insensitive to substitutions at either $\mathrm{C} 4$ or at C6. Other than the cyclitols, we have established that galactinol (1L-1-0- $a$-Dgalactopyranosyl myo-inositol), quebrachitol (1L-2-0-methyl chiro-inositol) and (-) quercitol $\left(1 \mathrm{~L}-1,3,4 / 2,5\right.$-cyclohexane pentol) are ineffective in stimulating the $\mathrm{L}_{\mathrm{I}}$ receptor. A postulated role for $m y o$-inositol as a taste factor in the mulberry leaf for the silkworm ${ }^{8}$ is of some interest, although the ubiquitous distribution of myo-inositol among plants and prevalence of inositol receptors among other lepidopteran larvae ${ }^{19}$ do not support the idea of a selective role for the inositol receptor in host-plant relationships.

The result obtained with the $\mathrm{L}_{\mathrm{I}}$ receptor of the silkworm indicate that the response magnitude is proportional to the number of receptor sites occupied by a stimulus molecule according to Beidler's taste equation, originally proposed for the salt receptor of the $\mathrm{rat}^{2}$ and subsequently applied to the labellar salt receptor responses of the fly ${ }^{7}$. Stimulation of the labellar sugar receptors of the fly by disaccharides shows similar kinetics but monosaccharides gave somewhat anomalous results ${ }^{16}$. These latter findings were interpreted to signify that either a sugar receptor site is composed of two subunits each of which is simultaneously occupied with a disaccharide or two monosaccharides or that allosteric transition occurred in the receptor site. Alternatively, the formation of a multimolecular complex between stimulating molecules and the receptor site has been suggested for the sweet receptor of the rat ${ }^{20}$. The present data are consistent with the idea that the two cyclitols are simply stimulating the same site and that this stimulation results from a $1: 1$ complex between the stimulus molecule and the receptor site. The cyclitol receptor would thus seem to be a useful system for receptor interactions. Unlike the fly, where relatively high concentrations of sugars are needed for receptor stimulation, the larval inositol receptor is several-fold more sensitive. In the tobacco hornworm, the lateral hair inositol receptor is reported to detect $5 \cdot 10^{-6} M$ inositol ${ }^{19}$. Such sensitivity may be important in view of the vitamin function of myo-inositol. While behavioral evidence for selection of a diet containing this vitamin is well known ${ }^{14}$, the mechanism for this selection is unknown and may be related to the present confirmation and extension of the work of Ishikawa et al. ${ }^{13}$. Not only is the unnatural cyclitol epi-inositol stimulatory at the Ss-I hair, but it appears to act at the $\mathrm{L}_{\mathrm{I}}$ receptor and with a similar threshold and saturation kinetics. It remains possible that still other natural myo-inositol derivatives play a role in the function of the $L_{I}$ hair. 


\section{SUMMARY}

The specificity of the 'sugar-sensitive' hair (Ss-I) in the silkworm to the 9 isomers of myo-inositol was studied electrophysiologically. Of the 9 isomers only myo-, epi- and allo-inositol elicited receptor activity. Using various mixtures of these cyclitols and sucrose it was determined that the inositol receptor located in the Ss-I hair responded only to myo- and epi-inositol while allo-inositol stimulated another receptor in the same hair. Threshold and magnitude of response of this receptor were nearly the same for both cyclitols. Configurational specificity of the inositol receptor and its role in taste and lipid metabolism are discussed.

\section{ACKNOWLEDGEMENTS}

This research was supported in part by Grants NS 04687 and MH 12506 from the National Institutes of Health.

\section{REFERENCES}

1 Agranoff, B. W., Bradley, R. M., and Brady, R. O., The enzymatic synthesis of inositol phosphatide, J. biol. Chem., 233 (1958) 1077-1083.

2 BeIDler, L. M., A theory of taste stimulation, J. gen. Physiol., 38 (1954) 133-139.

3 Benjamins, J. A., ANd Agranoff, B. W., Distribution and properties of CDP-diglyceride: inositol transferase from brain, J. Neurochem., 16 (1969) 513-527.

4 CANDY, D. J., Occurrence and metabolism of scyllo-inositol in the locust, Biochem. J., 103 (1967) 666-671.

5 Dethier, V. G., The physiology and histology of the contact chemoreceptor of the blowfly, Quart. Rev. Biol., 30 (1955) 348-371.

6 Evans, D. R., Chemical structure and stimulation by carbohydrates. In Y. ZotTerman (Ed.), Olfaction and Taste, Vol. 1, MacMillan, New York, 1963, pp. 165-176.

7 Evans, D. R., ANd Mellon, D., JR., Stimulation of a primary taste receptor by salts, J. gen. Physiol., 45 (1962) 651-661.

8 Hamamura, Y., Hayashiya, K., Naito, K., Matsuura, K., and Nishida, J., Food selection by silkworm larvae, Nature (Lond.), 194 (1962) 754-755.

9 Hodgson, E. S., Electrophysiological studies of arthropod chemoreception. II. Responses of labellar chemoreceptors of the blowfly to stimulation by carbohydrates, J. Insect Physiol., 1 (1957) 240-247.

10 Hodgson, E. S., AND RoEDER, K. D., Electrophysiological studies of arthropod chemoreception. I. General properties of labellar chemoreceptor of diptera, J. cell. comp. Physiol., 48 (1956) 51-75.

11 Ishikawa, S., Responses of maxillary chemoreceptors in the larva of the silkworm, Bombyx mori, to stimulation by carbohydrates, J. cell. comp. Physiol., 61 (1963) 99-107.

12 IsHIKAWA, S., Maxillary chemoreceptors in the silkworm. In T. HAYASHI (Ed.), Olfaction and Taste, Vol. 2, Pergamon, Oxford, 1967, pp. 761-777.

13 Ishikawa, S., Hirao, T., AND ARaI, N., Chemosensory basis of host plant selection in the silkworm, Ent. Exp. Appl., 12 (1969) 544-554.

14 Iто, T., Effect of sugars on feeding of larvae of the silkworm, Bombyx mori, J. Insect Physiol., 5 (1960) 95-107.

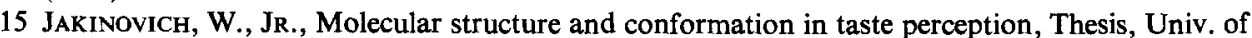
Michigan, Ann Arbor, 1970.

16 Morita, H., AND Shiraishi, A., Stimulation of the labellar sugar receptor of the fleshfly by monoand disaccharides, J. gen. Physiol., 52 (1968) 559-583.

17 Paulus, H., ANd Kennedy, E. P., The enzymatic synthesis of inositol monophosphatide, J. biol. Chem., 235 (1960) 1303-1311. 
18 Posternak, T., The Cyclitols, Hermann, Paris, 1965, pp. 303-310.

19 Schoonhoven, L. M., Gustation and foodplant selection in some lepidopterous larvae, Ent. Exp. Appl., 12 (1969) 555-564.

20 TATEDa, H., Sugar receptor and $\alpha$-amino acid in the rat. In T. HAYASHI (Ed.), Olfaction and Taste, Vol. 2, Pergamon, Oxford, 1967, pp. 383-397. 